\title{
Global Exchanges. Scholarships and Transnational Circulations in the Modern World
}

Diana Alejandra Méndez Rojas

Instituto de Investigaciones Dr. José María Luis Mora, México

damendezr@institutomora.edu.mx

Ludovic Tournès \& Giles Scott-Smith (eds.), Global Exchanges. Scholarships and Transnational Circulations in the Modern World, New York- Oxford, Berghahn, 2018, $344 \mathrm{pp}$.

El libro editado por Ludovic Tournès y Giles Scott-Smith, Global Exchanges. Scholarships and Transnational Circulations in the Modern World, constituye una propuesta original para conceptualizar y sistematizar la historia de los programas de becas internacionales. Por su importancia, el volumen destaca los esfuerzos emprendidos por gobiernos nacionales - algunos de ellos a través de la diplomacia cultural estadunidense y soviética-, los planes de intercambio de asociaciones religiosas, los trabajos de fundaciones filantrópicas como la Rockefeller, los de instituciones ligadas a la Organización de las Naciones Unidas y proyectos de la talla del Rhodes y Fullbright. La línea articuladora de la obra, conformada por diecinueve capítulos preparados por veintitrés autores, es el estudio de iniciativas oficiales que establecieron flujos de circulación de personas entre distintas naciones cuyo objetivo primordial fue fomentar procesos de aprendizaje, generalmente relacionados a políticas y prácticas modernizadoras. Asimismo, los escritos aproximan respuestas sobre la manera en que los programas de becas configuraron trayectorias profesionales, disciplinas, instituciones y culturas nacionales; a la vez que dan cuenta de las circunstancias que favorecieron que los programas fueran alterados por estos elementos.

\section{(c) (1) ()}

4.0 Internacional

Secuencia. Reseñas, 2021

http://secuencia.mora.edu.mx
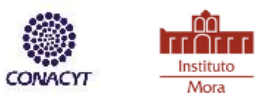


\section{Diana Alejandra Méndez Rojas}

El capitulado se inscribe dentro de la historia transnacional, una perspectiva que se especializa en la indagación sobre la estructuración de rutas de circulación e intercambio a distintas escalas considerando el peso de las ideas y las experiencias humanas. Geográficamente los estudios se sitúan principalmente en Europa y Estados Unidos, mientras que África y Asia son regiones incorporadas fundamentalmente en su relación con Europa, o bien en su vinculación con los Estados Unidos a partir de la descolonización. América Latina aparece en menciones menores a lo largo de las páginas del libro y la ausencia de un capítulo específico sobre el subcontinente es evidente, sobre esta cuestión ahondaré más adelante.

Tournès y Scott-Smith afirman que, pese a la importancia de los intercambios para la transferencia de conocimientos o la formación de redes globales, el estudio de los programas de becas no ha recibido la atención que merece de los historiadores; por lo que su especificidad ha sido supeditada a exploraciones desde la migración o las relaciones internacionales. Los editores sostienen su apreciación en un minucioso balance de la literatura relativa al tema el cual arroja que las aproximaciones históricas han fallado en cuanto a profundidad de análisis por dos motivos. De una parte, una escritura hagiográfica que ha promovido una visión institucional y sólo ha recuperado las historias de los becarios más exitosos y, de otra, el predominio de una visión construida con foco en los países del centro económico, que reduce la amplitud de la temática a la instrumentalización del soft power en la política internacional. Por lo anterior, esta obra colectiva se propone contribuir a la consolidación de un nuevo campo de investigación histórica con eje en la evaluación de los programas de becas y la recuperación de las vivencias y trayectorias de los becarios; reconociendo con ello que este tipo de iniciativas conjugan una pluralidad de aspectos técnicos, políticos, sociales, culturales y económicos.

De forma puntual, los editores postulan que los trabajos históricos sobre los programas de becas deben explicar y conjugar cuatro puntos: 1) El funcionamiento de los programas, esto es, su estructura y filosofía, así como su dimensión técnica y administrativa; 2) La relación de los programas y la política, es decir, sus imbricaciones con mutaciones en las políticas globales y el posicionamiento de instituciones internacionales; 3) Una perspectiva de largo alcance capaz de 


\section{Diana Alejandra Méndez Rojas}

reconstruir los itinerarios sociales, intelectuales y profesionales de los becarios antes, durante y después de sus estudios, con miras a complejizar el marco de referencia en la circulación transnacional; y 4) El vínculo entre los programas de becas y los valores económicos, en la forma de financiamiento y fortalecimiento de la economía.

Por lo hasta aquí dicho, el reto que asumen los autores de esta obra es estudiar la forma en que los programas de becas han participado en la construcción y circulación del conocimiento global, al tiempo de configurar pautas para el desempeño profesional y disciplinar en las ciencias médicas, las sociales, las agrícolas y del deporte, por mencionar solo algunos casos. Desde distintos ángulos, los capítulos combinan una perspectiva centrada en las instituciones oferentes (una mirada de arriba a abajo) y un enfoque desde los becarios (una mirada de abajo hacia arriba).

En cuanto a los criterios que definen la periodización del libro, los estudios reunidos sugieren que el examen global de los programas de becas debe considerar un marco temporal amplio que reconoce su inicio formal a mediados del siglo XIX y se extiende hasta la actualidad, teniendo como puntos de recambio el período de entreguerras, la Guerra Fría y la reciente globalización. Se indica así que los primeros planes de becas fueron resultado de la afirmación de los estados-nación en la escena internacional y su afán de competencia por el liderazgo en educación, ciencia y economía; uno de los mejores ejemplos en esta vertiente es el del Imperio Británico que, entre 1860 e inicios del siglo XX, promovió el desplazamiento de los mejores estudiantes de las colonias hacia la metrópoli con el objetivo de reforzar su conexión. A partir del período de entreguerras las becas apostaron por la construcción de una comunidad universal del conocimiento, de mantenimiento de la paz y de la cooperación internacional; ideas que se desprendieron en mayor medida de la filantropía científica estadunidense. La Guerra Fría fue la "edad de oro" de los programas de becas y Estados Unidos logró afirmar su liderazgo gracias a la competencia con los programas soviéticos, pues ambas potencias buscaron promover sus modelos político-económicos a través de la cooperación científica y técnica. Desde 1970, el rasgo distintivo de la era de la globalización fue el deterioro 


\section{Diana Alejandra Méndez Rojas}

de la preminencia estadunidense, entre otras razones, a causa de cambios en su política internacional y reformas domésticas en materia fiscal. Esta circunstancia favoreció el ascenso de proyectos creados en India, China y la Unión Europea, el programa Erasmus forma parte de esta tendencia.

Al comienzo de esta reseña apunté que el libro en cuestión no incluye un capítulo dedicado exclusivamente a algún programa de becas en América Latina. La ausencia de esta región genera un desequilibrio dentro de la propuesta general del volumen que busca aportar un modelo de comprensión para la multiplicidad de expresiones de los programas de becas y contribuir a la construcción de una visión global del fenómeno. ¿Cuáles son los estímulos que abre esta obra a los interesados por esta línea de investigación desde América Latina? Las respuestas pueden ser múltiples, según la inclinación particular del lector, aquí propongo tres. Primeramente, analizar la consistente argumentación del capitulado, un esfuerzo colectivo con el mérito de apostar por el afianzamiento del estudio histórico de los programas de becas como un campo propio con preguntas y procedimientos específicos, capaces de explicar la transferencia de conocimientos, el intercambio cultural y la conformación de redes.

En segundo lugar, el volumen invita a cavilar sobre las cualidades de los programas de becas que desde el extranjero se insertaron en América Latina, entre ellos, los promovidos por fundaciones estadunidenses. La obra editada por Tournès y Scott-Smith es patente al señalar que pese a la existencia de lineamientos fundantes por parte de las instituciones oferentes la extensión de sus programas de becas en contextos específicos requirió que se adecuara su marco operativo, circunstancia que dotó de características propias a cada experiencia. Los estudios de Adriana Minor (2019) y Fernando Quesada (2020) muestran algunos de los ritmos del programa Rockefeller en la región para la física y la agricultura. En otro sentido, es importante remarcar que América Latina no solo ha sido receptora de becas pues también las ha otorgado, así lo demuestra la existencia temprana de programas promovidos por los gobiernos venezolano y mexicano que antecedieron a la Segunda Guerra Mundial. Estas iniciativas han sido estudiadas por Humberto Ruiz (1997), Sebastián Rivera Mir (2012) y Vinicio Calderón (2019). 


\section{Diana Alejandra Méndez Rojas}

Si bien el libro busca aprehender la especificidad de los programas de becas y en esto radica su originalidad, una tercera tarea por realizar es un detallado contrapunteo de sus proposiciones con marcos de referencia latinoamericanos que permitan ponderar el entrecruzamiento de la movilidad internacional con otros procesos subcontinentales, por ejemplo: el exilio y las prácticas políticas transnacionales. En esta línea, Rivera Mir (2020) ha elaborado una amplia propuesta sobre el intercambio académico que resalta el papel articulador de México a escala continental. Para concluir es oportuno remarcar que la producción académica reciente sugiere que el estudio de los programas de becas está cobrando interés, dentro y fuera de América Latina, por lo que la lectura de obras como Global Exchanges es fundamental para la construcción de marcos interpretativos situados.

\section{Referencias}

Calderón, V. (2019). El águila al sur del nopal: la política exterior entre México y Costa Rica (1917-1940). (Tesis de maestría inédita). Universidad de Costa Rica.

Minor, A. (2019). The Rockefeller Foundation (Non) Policy Toward Physics Research and Education in Latin America. En Research Report (pp. 1-16). New York: Rockefeller Archive Center.

Quesada, F. (2020). La Fundación Rockefeller y la construcción de una red de expertos agrícolas en Chile (1942-1970). En B. Figallo (comp.), Diplomáticos y hacedores de las relaciones internacionales. Protagonismos, testimonios y fuentes en la política exterior argentina y latinoamericana (pp. 191-205). Ciudad Autónoma de Buenos Aires: Fundación CICCUS.

Rivera Mir, S. (2012). La experiencia de los centroamericanos becados en México (1922-1928). Entre carencias, vida académica y propaganda revolucionaria.

Latinoamérica, 55(2), 185-214.

http://latinoamerica.unam.mx/index.php/latino/article/view/56506/50180

Rivera Mir, S. (coord.). (2020). Historias entrelazadas. El intercambio académico en el siglo XX: México, Estados Unidos, América Latina. México: El Colegio Mexiquense.

Ruiz, H. (1997). Tras el fuego de Prometeo. Becas en el exterior y modernización en Venezuela (1900-1996). Venezuela: Nueva Sociedad. 